\title{
Primary Small Cell Carcinoma of Liver in a HIV/Hepatitis B Co-Infected Patient on Virologically Suppressive Antiretroviral Therapy: Case Report and Literature Review
}

Ameet Dravid ${ }^{1 *}$, Kartik Natarajan'1, Mahenderkumar Medisetty', Vinay Thorat', Sujit Joshi², Mahesh Mandolkar², Sujit Nilegaonkar², Deepak Phalgune ${ }^{1}$, Chinmay Saraf ${ }^{3}$, Milind Kulkarni ${ }^{3}$ and Padmaj Kulkarni ${ }^{1,2}$

${ }^{1}$ Poona Hospital and Research Center, Pune, Maharashtra, India

${ }^{2}$ Deenanath Mangeshkar Hospital, Pune, Maharashtra, India

${ }^{3}$ Precision Diagnostics and Biosciences, Pune, Maharashtra, India

\begin{abstract}
Primary small cell carcinoma of the liver is a rare tumor with few cases reported worldwide. We report a case of primary small cell carcinoma of the liver in a HIV/Hepatitis B co-infected patient on Tenofovir based virologically suppressive antiretroviral therapy (ART). Patient presented with fatigue and vomiting, two years after starting ART. CT abdomen showed hepatomegaly with diffuse infiltration. Liver biopsy established a diagnosis of small cell cancer of liver. Immunohistochemistry results were positive for synaptophysin and CD56 while they were negative for Hep par antibody stain 1. Positron Emission Tomography (PET) scan suggested a diagnosis of malignant neoplasm in the liver. Chemotherapy was started which led to hyperacute liver failure. Patient recovered from liver failure and received 3 cycles of chemotherapy. PET scan done at 3 months showed complete regression of neoplasm but prior to start of $4^{\text {th }}$ cycle, neoplasm relapsed, and patient died 15 days later. Here we discuss the clinical course and treatment of a case of primary small cell carcinoma (SCC) of the liver and review the literature regarding this rare cancer.
\end{abstract}

Keywords: HIV; Hepatitis B; Antiretroviral Therapy (ART); Primary small cell carcinoma of liver; Neuroendocrine tumor

\section{Introduction}

Based on the 2010 World Health Organization (WHO) histological classification, a neuroendocrine tumor can be classified as a 'well-differentiated neuroendocrine tumor, well-differentiated neuroendocrine carcinoma or a poorly differentiated neuroendocrine carcinoma. Poorly differentiated neuroendocrine carcinomas are highly aggressive malignancies and most of them are Small Cell Carcinomas (SCC). SCC is mostly found in the lungs, and $25 \%$ of lung carcinomas are SCC [1]. Duguid and Kennedy in 1930 reported extrapulmonary SCC (EPSCC) as a clinicopathological entity [2]. About $2 \%$ to $4 \%$ of SCC have been reported from extrapulmonary sites like the head, neck, salivary glands, thyroid, larynx, trachea, thymus, pleura, esophagus, stomach, intestines, rectum, pancreas, gall bladder, cervix, uterus, breast, prostate, urinary bladder, and skin [1]. Primary SCC of the liver is rare with few cases reported worldwide. We report a case of HIV/Hepatitis $\mathrm{B}$ co-infected patient taking Tenofovir based ART and presenting with primary SCC of liver.

\section{Case Report}

A 48-years-old male presented with fatigue, anorexia and vomiting for a period of 15 days. He was afebrile and there was no abdominal pain. Patient was diagnosed with HIV and Hepatitis B (HBV) co-infection 2 years ago with a baseline CD 4 count of 189 cells $/ \mathrm{mm}^{3}$. He was currently on ART with Tenofovir, Emtricitabine and ritonavir boosted Atazanavir since the last 15 months. Patient had no history of any addictions. Icterus was present, and liver was moderately enlarged. Hemoglobin was $10.3 \mathrm{gm} \%$, serum bilirubin was $2.34 \mathrm{mg} / \mathrm{dl}$, direct bilirubin was $0.6 \mathrm{mg} / \mathrm{dl}$, aspartate transaminase (AST) and alanine transaminase (ALT) were 49/55 IU/L, alkaline phosphate was $506 \mathrm{IU} / \mathrm{L}$, absolute CD4 count was 278 cells $/ \mathrm{mm}^{3}$ and plasma HIV-1 viral load was $<20$ copies/ $\mathrm{ml}$. Indirect hyperbilirubinemia was attributed to ritonavir boosted Atazanavir. Virologic markers revealed the following: $\mathrm{HBsAg}(+)$, antiHBs (-), HBeAg (-) and anti-HCV (-). HBV DNA was undetectable. USG abdomen showed moderate hepatomegaly. CT abdomen showed hepatomegaly with diffuse infiltration suggestive of neoplasm (Figure 1). Liver biopsy and histopathology was suggestive of SCC of the liver. Carcinoma exhibited diffuse sinusoidal infiltration of small blue neoplastic cells almost entirely replacing the hepatic parenchyma. Immunohistochemically, the tumor revealed neuroendocrine differentiation (Figure 2). Immunohistochemistry results were positive for synaptophysin and negative for chromogranin stain. CD56 was
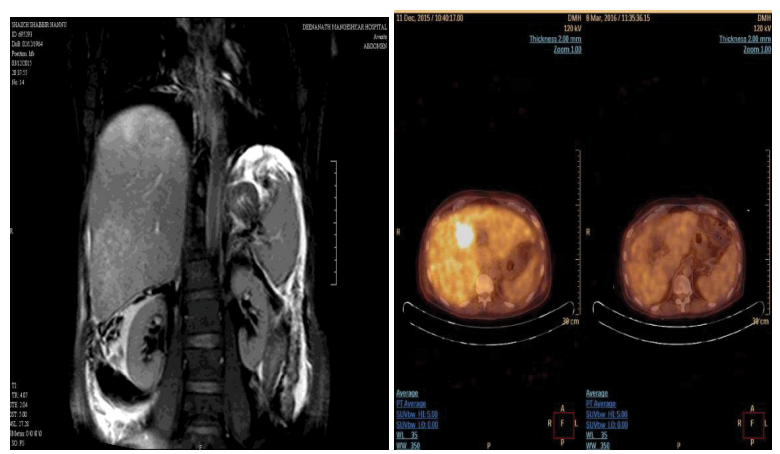

Figure 1: CT abdomen and PET scan images of primary small cell cancer of liver.

*Corresponding author: Ameet Dravid, Poona Hospital and Research Center Sadashiv Peth, Pune, Maharashtra, 411004, India, Tel: 09975619766; E-mail ameet.dravid@gmail.com

Received: September 29, 2017; Accepted: October 24, 2017; Published: October 26, 2017

Citation: Dravid A, Natarajan K, Medisetty M, Thorat V, Joshi S, et al. (2017) Primary Small Cell Carcinoma of Liver in a HIV/Hepatitis B Co-Infected Patient on Virologically Suppressive Antiretroviral Therapy: Case Report and Literature Review. Oncol Cancer Case Rep 3: 137.

Copyright: $\odot 2017$ Dravid A, et al. This is an open-access article distributed under the terms of the Creative Commons Attribution License, which permits unrestricted use, distribution, and reproduction in any medium, provided the original author and source are credited. 


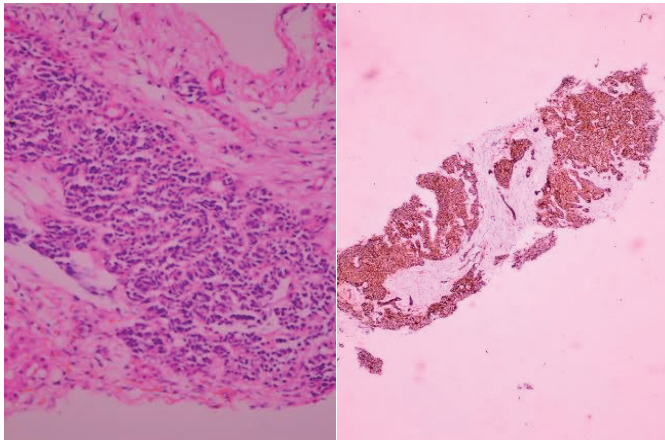

Figure 2: Histopathology and Immunohistochemistry.

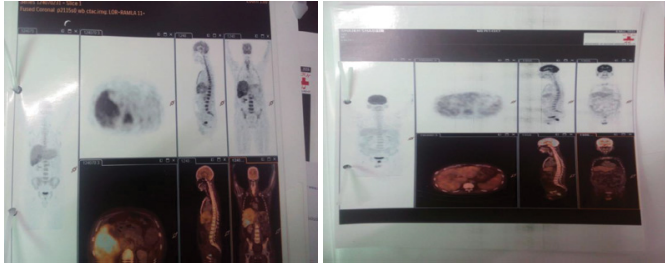

Figure 3: PET scan pre and post chemotherapy

weakly positive and Hep par antibody stain 1 was negative. Positron Emission Tomography (PET) scan showed that the patient had primary small cell cancer of the liver with no lymph node or organ metastasis (Figure 3).

Patient was given intravenous (IV) etoposide $\left(60 \mathrm{mg} / \mathrm{m}^{2}\right)$ and carboplatin $\left(80 \mathrm{mg} / \mathrm{m}^{2}\right)$ along with ART. As soon as chemotherapy was started, patient developed hyper-acute liver failure. Total Bilirubin, Direct Bilirubin, AST and ALT were $22.1 \mathrm{mg} / \mathrm{dl}, 18.4 \mathrm{mg} / \mathrm{dl}, 1381$ $\mathrm{IU} / \mathrm{L}$ and $2566 \mathrm{IU} / \mathrm{L}$ respectively. With institution of conservative management in intensive care unit all parameters returned to normal in the next one month. Patient was given three cycles of chemotherapy. Repeat PET scan was suggestive of complete resolution of malignancy (Figure 3). However, 3 days prior to start of $4^{\text {th }}$ cycle, SCC relapsed, and patient died 15 days later due to hyperacute liver failure and bacterial sepsis.

\section{Discussion}

We report a case of primary small cell carcinoma of the liver in a HIV/HBV co-infected patient on ART. Very few cases have been reported till date [3,4,5-15]. Neuroendocrine tumors arise from embryonic neural crest cells that migrate to bronchopulmonary or gastrointestinal tract during development. These cells seldom migrate to the liver; hence primary hepatic neuroendocrine tumors are rare [5]. There are only two case reports of primary hepatic SCC in a patient with underlying liver disease such as chronic hepatitis B or liver cirrhosis. Khaw et al. [3] reported primary liver SCC developing along with hepatocellular carcinoma and cholangiocarcinoma in a patient with underlying cirrhosis. Suk [4] has described a case of primary hepatic SCC in a patient with HBV induced liver cirrhosis who was on Entecavir therapy and had an undetectable HBV DNA. To the best of our knowledge, ours is the first case report of primary SCC of liver in a HIV/HBV co-infected infected patient. Metastatic SCC in the liver presents with multiple liver nodules but primary SCC exhibits a diffusely sinusoidal infiltrative pattern. Immunohistochemistry might help in distinguishing primary SCC from metastatic SCC of liver.
Thyroid transcription factor 1 (TTF-1) is usually positive (96\%) in small-cell lung cancer but negative in EPSCC [6]. In our case, TTF-1 was not performed but PET excluded any extra hepatic primary source.

In general, the treatment of EPSCC is organ resection and adjuvant chemotherapy using the same regimen as with pulmonary SCC. However, SCC frequently shows distant metastasis and consequently has a poor prognosis. Kaman et al. [7] reported that in their patient, tumor arose from segment IV, V and VIII of liver and the patient underwent central bisectionectomy followed by combined chemotherapy for the same. Three cases of primary hepatic SCC were reported by Zanconati [8], out of which one patient was treated by mass resection whereas two others did not receive any therapy. The clinical progression was rapid, and death occurred within five months after diagnosis. Sengoz et al. [9] reported two cases; one patient received chemotherapy whereas hemihepatectomy was performed on another. The survival of the patients was 13 and 67 months respectively. Kim et al. [10] reported a patient who underwent segmentectomy of the liver along with chemotherapy. The patient survived with no signs of recurrence for four months. In other 5 reported cases, two patients received combined chemotherapy $[11,12]$, and two underwent resection $[13,14]$ whereas one received no treatment [1]. Isobe et al. [15] described the case of liver SCC refractory to cisplatin, etoposide and irinotecan showing regression after starting amrubicin monotherapy with a 26-month survival. Our patient received combination chemotherapy which let to complete regression of cancer followed by swift relapse within 4 months.

\section{Conclusion}

Here, the case of a HIV/hepatitis B co-infected patient on virologically suppressive ART presenting with primary hepatic SCC is reported, together with a literature review. This will contribute to developing knowledge on the natural course of primary hepatic SCC and effective treatment strategies for this deadly cancer.

\section{References}

1. Kim KO, Lee HY, Chun SH, Shin SJ, Kim MK, et al. (2006) Clinical overview of extrapulmonary small cell carcinoma. J Korean Med Sci 21: 833-837.

2. Duguid JB, Kennedy AM (1930) Oat-cell tumors of mediastinal glands. J Patho 33: 93-99.

3. Khaw YL, Nolan N, Heaslip I, McCormick PA, Sheaha K (2011) Primary intrahepatic small-cell carcinoma arising from combined hepatocellular and cholangiocarcinomas. J Clin Oncol 29: e630-633.

4. Suk BK (2015) Primary hepatic small-cell carcinoma developed during antivira treatment for chronic hepatitis B. Case Rep Gastroenterol 9: 375-380.

5. Levenson RM, Ihde DC, Matthews MJ, Cohen MH, Gazdar AF, et al. (1981) Small cell carcinoma presenting as an extrapulmonary neoplasm: sites of origin and response to chemotherapy. J Natl Cancer Inst 67: 607-612.

6. Ordonez NG (2000) Value of thyroid transcription factor-1 immunostaining in distinguishing small cell lung carcinomas from other small cell carcinomas. Am J Surg Pathol 24: 1217-1223.

7. Kaman L, Iqbal J, Pall M, Bal A (2010) Primary small cell carcinoma of liver: A rare tumor. Gastroenterology Res 3: 180.

8. Zanconati F, Falconieri G, Lamovec J, Zidar A (1996) Small cell carcinoma of the liver: A hitherto unreported variant of hepatocellular carcinoma. Histopathology 29: $449-453$.

9. Sengoz M, Abacioglu U, Salepci T, Eren F, Yumuk F, et al. (2002) Extrapulmonary small cell carcinoma: Multimodality treatment results. Tumori 89: 274-277.

10. Kim YH, Kwon R, Jung GJ, Roh MH, Han SY, et al. (2004) Extrapulmonary small-cell carcinoma of the liver. J Hepatobiliary Pancreat Surg 11: 333-337.

11. Ryu SH, Han SY, Suh SH, Koo YH, Cho JH, et al. (2005) A case of primary small cell carcinoma of the liver. Korean J Hepatol 11: 289-292. 
Citation: Dravid A, Natarajan K, Medisetty M, Thorat V, Joshi S, et al. (2017) Primary Small Cell Carcinoma of Liver in a HIV/Hepatitis B Co-Infected Patient on Virologically Suppressive Antiretroviral Therapy: Case Report and Literature Review. Oncol Cancer Case Rep 3: 137.

Page 3 of 3

12. Choi SJ, Kim JM, Han JY, Ahn SI, Kim JS, et al. (2007) Extrapulmonary small cell carcinoma of the liver: Clinicopathological and immunohistochemical findings. Yonsei Med J 48: 1066-1071.

13. Kim KJ, Yim HJ, Kim MJ, Choung RS, Yeon JE, et al. (2006) A case of primary small cell neuroendocrine Carcinoma of the liver. Korean J Gastroenterol 48: $37-41$.
14. Huang YQ, Xu F, Yang JM, Huang B (2010) Primary hepatic neuroendocrine carcinoma: Clinical analysis of 11 cases. Hepatobiliary Pancreat Dis Int 9 : 44-48.

15. Isobe T, Yanai S, Kusaba H, Yada S, Kuroda Y, et al. (2009) Effective monotherapy with amrubicin for a refractory extrapulmonary small-cell carcinoma of the liver. Case Rep Med 2009: 538081. 